\title{
Effects of delivery by caesarean section on lung mechanics and lung volume in the human neonate
}

\author{
A. D. MILNER, R. A. SAUNDERS, AND I. E. HOPKIN \\ From the Department of Child Health, University Hospital and Medical School, Nottingham
}

SUMMARY Lung function tests were carried out in the first 6 hours of life on 26 babies born by vaginal delivery and 10 born by caesarean section. The babies born by caesarean section had a mean thoracic gas volume of only $19.7 \mathrm{ml} / \mathrm{kg}$ body weight compared with $32.7 \mathrm{ml} / \mathrm{kg}$ for the babies born vaginally. We conclude that this is owing to an excess of lung fluid in the babies born by caesarean section.

It is well established that during vaginal delivery the infant's thoracic cage is subjected to considerable external compression which tends to express lung fluid from the infant's nose and mouth. Karlberg et al. (1962) measured intrathoracic pressure changes rising to as high as $9.0 \mathrm{kPa}\left(90 \mathrm{~cm} \mathrm{H}_{2} \mathrm{O}\right)$. In a recent study we found that the intrathoracic pressure as measured by a water-filled catheter in the oesophagus may rise by as much as $16 \mathrm{kPa}$ $\left(160 \mathrm{~cm} \mathrm{H}_{2} \mathrm{O}\right.$ ) during the delivery of the thorax and that this may be associated with a reduction in lung volume of up to $35 \mathrm{ml}$ (Saunders and Milner, 1977, unpublished). It has been assumed that the infants born by caesarean section are placed at a disadvantage through not experiencing thoracic compression, and that this may partly explain the increased morbidity and mortality often associated with this type of delivery (Benson et al., 1969; Butler and Alberman, 1969; Hack et al., 1976). It is probable that when the gestational age is $>37$ weeks elective caesarean section does not predispose to the respiratory distress syndrome (Usher et al., 1971). In preterm babies it has proved difficult to separate the influences of asphyxia, immaturity, and delivery by caesarean section on the incidence of respiratory distress. Attempts have been made to mimic vaginal compression by giving ergometrine before the delivery of the shoulders and the trunk through the uterine incision, apparently with improvement in perinatal mortality (Reis et al., 1970).

Surprisingly there is a dearth of data on the effect of delivery by caesarean section on lung function in the immediate postnatal period. Two studies have shown that the crying vital capacity is reduced in

Received 22 December 1977 babies born by caesarean section compared with those born vaginally (Chiswick and Milner, 1976; Brice and Walker, 1977). Other studies on blood gas changes in the hours after elective caesarean section suggest that these babies had higher arterial $\mathrm{CO}_{2}$ and hydrogen iron concentrations but that their $\mathrm{O}_{2}$ tensions surprisingly were virtually identical with babies born vaginally (Kjellmer et al., 1974; Magno et al., 1975, 1976). The aim of this project was to determine whether vaginal compression has any measurable effect on lung mechanics and lung volumes in the hours after birth, by comparing results on babies born by caesarean section with those born vaginally.

\section{Method}

All measurements were carried out in a speciallyconstructed, 48-litre, cylindrical, total body plethysmograph, in which babies were nursed in the right lateral position. Except during periods of shutter closure there was a continuous bias flow of air through the face mask at the rate of $31 / \mathrm{min}$. The gases were conducted across a pneumotachograph, through a shutter system, and out through a port in the side of the plethysmograph. Lower oesophageal pressure was simultaneously measured using a thin-walled, latex balloon mounted on a 6 FG feeding catheter. All the signals were relayed via an amplification system to a four-channel FM recorder. Further details of the apparatus are given in previous publications (Saunders et al., 1976; Milner et al., 1977).

Using this system we were able to measure tidal Volume $\left(V_{T}\right)$, respiratory frequency $(f)$, expiratory minute volume $\left(\dot{\mathrm{V}}_{\mathrm{E}}\right)$ and, by simultaneous analysis 
of the pressure, volume and flow traces, the dynamic compliance $\left(C_{D}\right)$, and midvolume total pulmonary resistance $\left(\mathrm{TPR}_{50}\right)$ (Cooke et al., 1957). The thoracic gas volume (TGV) was measured by relating the intrapulmonary pressure changes to the plethysmographic volume changes during periods of shutter closure for up to 10 seconds (DuBois et al., 1956; Auld et al., 1963). At least 6 breaths were studied for each parameter and the mean values were then calculated.

\section{Subjects}

Two groups of babies were studied. Group 1 comprised 26 babies born by vaginal delivery. Two were breech presentations requiring forceps delivery. Forceps were used on 2 other occasions: once for fetal distress in the second stage and once for maternal distress. All were at term (mean 39.7, range 38-41 weeks) with a mean birthweight of $3.12 \mathrm{~kg}$ (range $2 \cdot 00-3 \cdot 9 \mathrm{~kg}$ ). One of the babies born by breech required intubation at 2 minutes, and another, born by unassisted vertex delivery, was intubated at 4 minutes. Both responded rapidly to intermittent positive pressure ventilation and were extubated within 5 minutes. Group 2 comprised 10 babies born by caesarean section. Their gestational ages ranged from 37-40 weeks (mean 39.1) and their birthweight ranged from 1.80 to $3.93 \mathrm{~kg}$ (mean $3.25 \mathrm{~kg}$ ). The reasons for caesarean section and the anaesthetic agent given to the mother are shown in Table 1. Ergometrine was given intravenously as soon as the baby had been lifted out of the uterine cavity. The cord was clamped with the baby at approximately the same level as the mother's uterus. Three of the babies required intubation at the stages of 1,2 , and 4 minutes respectively. None was severely asphyxiated and all responded rapidly to resuscitation. All babies were studied between the ages of $1 \frac{1}{2}$ and 6 hours. The mean age for group 1 was 3.8 hours and that for group 2 babies at the time of study was 3.95 hours. One of the group 2 babies was studied at both 2 and 5 hours of age. After the initial resuscitation none of the babies had any clinical evidence of cardiac or respiratory disease and none required oxygen. Chest circumference was measured at the midsternal point.

Informed maternal consent was obtained on all occasions and the project was submitted in advance and passed by the local ethical committee.

\section{Results}

Although $V_{T}, \dot{V}_{E}$, and $C_{D}$ tended to be lower and $T_{P R}$ higher in the babies born by caesarean section, these differences did not reach statistical significance (Table 2). Striking differences, however, were apparent in the thoracic gas volume measurements

Table 1 Indications for caesarean section (LSCS), anaesthetic used, and resuscitation required in the 10 babies in group 2

\begin{tabular}{|c|c|c|c|}
\hline Case & Indication for LSCS & Anaesthetic for LSCS & Resuscitation \\
\hline 1 & Fetal distress & Epidural-thiopentone, nitrous oxide + oxygen & $\begin{array}{l}\text { Intubated at } 1 \text { minute for low } \\
\text { fetal heart rate }\end{array}$ \\
\hline 2 & Disproportion & Epidural & Oropharyngeal suction \\
\hline 3 & Breech presentation. Failure to progress & Epidural & $\begin{array}{l}\text { Intubated at } 4 \text { minutes for } \\
\text { inadequate respiratory efforts }\end{array}$ \\
\hline 4 & Pre-eclamptic toxaemia & Thiopentone, nitrous oxide + oxygen & $\begin{array}{l}\text { Intubated at } 2 \text { minutes for } \\
\text { inadequate respiratory efforts }\end{array}$ \\
\hline 5 & Maternal diabetes & Thiopentone, nitrous oxide + oxygen & Oropharyngeal suction \\
\hline 6 & Breech in elderly primagravida & Thiopentone, nitrous oxide + oxygen & Oropharyngeal suction \\
\hline 7 & Pre-eclamptic toxaemia & Thiopentone, nitrous oxide + oxygen & Oropharyngeal suction \\
\hline 8 & Falling placental function & Thiopentone, nitrous oxide + oxygen & Oropharyngeal suction \\
\hline 9 & Breech. Small maternal stature & Thiopentone, nitrous oxide + oxygen & Oropharyngeal suction \\
\hline 10 & Disproportion and failure to progress & Epidural, nitrous oxide + oxygen & Oropharyngeal suction \\
\hline
\end{tabular}

Table 2 Respiratory rate $(f)$, total volume $(T V)$, minute volume $\left(\dot{V}_{E}\right)$, dynamic compliance $\left(C_{D}\right)$, total pulmonary resistance (TPR $\left.\mathrm{B}_{\mathrm{5}}\right)$, and thoracic gas volume (TGV) in 26 babies born vaginally, and 10 babies studied on 11 occasions born by caesarean section. The mean and $\pm 1 S D$ is shown for each group

\begin{tabular}{|c|c|c|c|c|c|c|}
\hline & $\begin{array}{l}f \\
(/ \min )\end{array}$ & $\begin{array}{l}T V \\
(m l)\end{array}$ & $\begin{array}{l}\dot{V}_{\mathrm{E}} \\
(\mathrm{ml} / \mathrm{min})\end{array}$ & $\begin{array}{l}C_{\mathrm{D}} \\
(m l / k P a)\end{array}$ & $\begin{array}{l}T P R_{50} \\
(k P a / l p e r s)\end{array}$ & $\begin{array}{l}\text { TGV } \\
(\mathrm{ml} / \mathrm{kg} \text { body weight) }\end{array}$ \\
\hline $\begin{array}{l}\text { Group } 1 \\
\text { born vaginally }\end{array}$ & $\begin{array}{c}44 \cdot 5 \\
(10 \cdot 5)\end{array}$ & $\begin{array}{l}15 \cdot 9 \\
(4 \cdot 4)\end{array}$ & $\begin{array}{l}706 \cdot 1 \\
(329)\end{array}$ & $\begin{array}{c}5 \cdot 70 \\
(3 \cdot 52)\end{array}$ & $\begin{array}{c}43 \cdot 2 \\
(25 \cdot 2)\end{array}$ & $\begin{array}{l}32 \cdot 7 \\
(8 \cdot 9)\end{array}$ \\
\hline $\begin{array}{l}\text { Group } 2 \\
\text { born by caesarean section }\end{array}$ & $\begin{array}{c}42 \cdot 0 \\
(11 \cdot 3)\end{array}$ & $\begin{array}{l}13 \cdot 8 \\
(3 \cdot 84)\end{array}$ & $\begin{array}{l}609 \cdot 5 \\
(197)\end{array}$ & $\begin{array}{c}4 \cdot 45 \\
(1 \cdot 88)\end{array}$ & $\begin{array}{c}46 \cdot 7 \\
(34 \cdot 2)\end{array}$ & $\begin{array}{l}19 \cdot 7 \\
(4 \cdot 75)\end{array}$ \\
\hline Significance (P) & 一 & 0.13 & 0.10 & $0 \cdot 10$ & - & $<0.0001$ \\
\hline
\end{tabular}


(Figure). The mean TGV after vaginal delivery was $32.7 \mathrm{ml} / \mathrm{kg}$ (SD \pm 8.9$)$; after caesarean section it was only $19 \cdot 7 \mathrm{ml} / \mathrm{kg}$ (SD $\pm 4 \cdot 7)$. The difference between the two groups was highly significant $(P<0.0001)$. The two babies born by breech delivery had TGVs of 24.5 and $24.2 \mathrm{ml} / \mathrm{kg}$ respectively. However, chest circumferences were the same in both groups (group 1 mean $31.8 \mathrm{~cm} \mathrm{SD} \pm 2 \cdot 5$; group $232 \cdot 3 \mathrm{~cm} \mathrm{SD} \pm 2 \cdot 6$ ).

\section{Discussion}

As anticipated the babies born by caesarean section had stiffer lungs and higher total pulmonary resistance, but lower tidal and minute volumes compared with those born vaginally. Surprisingly the respiratory rates were virtually identical in the two groups. These differences, however, were small and did not reach statistical significance. The TGVs at functional residual capacity were much lower in the babies in group 2 than in those born by vaginal delivery. There are two possible explanations for this. The first is that the anaesthetic agents used at caesarean section may have led to a fall in total thoracic volume. Recent work on lung expansion at birth (Milner et al., 1977), studies on the effects of continuous distending pressure on lung mechanics and lung volume (Saunders et al., 1976), and studies on fresh stillborn infants, indicate that muscle tone is of considerable importance in the maintenance of the stability of the chest wall. From these findings

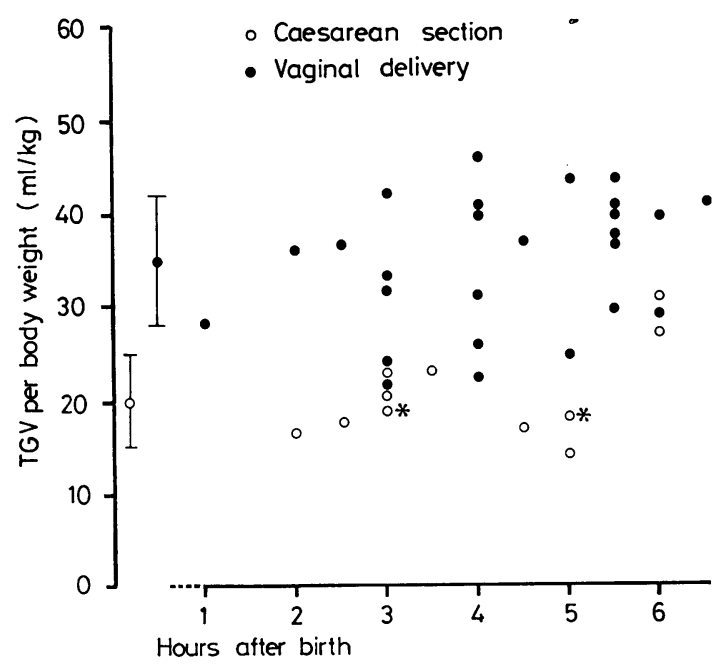

Figure Thoracic gas volume per $\mathrm{kg}$ body weight (TGV) related to postnatal age in 26 babies born vaginally and 10 babies born by caesarean section. One baby born by caesarean section was studied on two occasions $\left(^{*}\right)$. we would expect that any agent that reduces respiratory muscle tone leads to a reduction in overall lung volume.

The second explanation is that infants not exposed to vaginal compression will have excessively high volumes of interstitial and alveolar fluid for the first few hours of life, so that although TGV will be reduced, the overall thoracic volume will be within the normal range. Chest circumference measurements were identical in both groups, favouring this second explanation. It is also interesting that the 2 babies born by breech delivery had relatively low TGVs, since expulsion of lung fluid is less likely to be as efficient in this mode of delivery. Whether this waterlogging is important remains unknown, but it would not be surprising if this situation led to a rise in respiratory rates with or without grunting, presenting a clinical picture of mild respiratory distress. When surfactant is also deficient this waterlogging may be of greater clinical significance.

It is also well known that the time of the cord clamping has an important effect on breathing pattern and lung mechanics in the immediate neonatal period. It has been shown that, provided the baby is nursed at approximately the same level as the mother until the cord is clamped, the circulating blood volume will not differ from that found in babies born vaginally (Sisson et al., 1973). It has been suggested that pulmonary perfusion may be important in the maintenance of the lung volume immediately after delivery (Avery et al., 1958). However, if the TGV were low owing to a reduction in blood volume and pulmonary perfusion, this again would be reflected in the chest wall circumference.

The time required to clear the excess fluid from the lungs has yet to be evaluated. Interestingly two babies in group 2 at 5 to 6 hours of age had TGVs of 31.5 and $27.1 \mathrm{ml} / \mathrm{kg}$, suggesting that the differences may last only for a few hours. It is well established that after birth there is a steep increase in lymphatic drainage from the lungs and that this route, in addition to the pulmonary capillary bed, is important in the clearance of excessive lung fluid within a few hours of birth (Humphreys et al., 1967). It may be that these mechanisms are sufficient to clear the large volume of fluid present in the lungs of babies born by caesarean section within 6 hours of birth.

Our conclusions from this study are that in the first few hours of life babies born by caesarean section at term have overall lung volumes similar to those born by vaginal delivery, but that the liquid volume is increased and the gaseous component decreased. This finding would explain the increased 
incidence of mild, transient, respiratory signs in these babies.

Financial support for this project was gratefully received from Action Research for the Crippled Child.

\section{References}

Auld, P. A. M., Nelson, N. M., Cherry, R. B., Rudolf, A. M., and Smith, C. A. (1963). Measurement of thoracic gas volume in the newborn infant. Journal of Clinical Investigation, 42, 476-483.

Avery, M. E., Frank, N. R., and Cribetz, I. (1958). Effects of vascular distension on inflation of the newborn lung (abstract). American Journal of Diseases of Children, 96, 505-506.

Benson, R. C., Berendes, H., and Weiss, W. (1969). Fetal compromise during elective cesarean section. American Journal of Obstetrics and Gynecology, 105, 579-588.

Brice, J. E. H., and Walker, C. H. M. (1977). Changing patterns of expiratory distress in newborn. Lancet, 2, 752-754.

Butler, N. R., and Alberman, E. D. (1969). Perinatal Problems. Second Report of the 1958 British Perinatal Mortality Survey. Livingstone: Edinburgh.

Chiswick, M. L., and Milner, R. D. G. (1976). Crying vital capacity: measurement of neonatal lung function. Archives of Disease: in Childhood, 51, 22-27.

Cooke, C. S., Sutherland, J. M., Segal, S., Cherry, R. B., Mead, J., McIlroy, M. D., and Smith, C. A. (1957). Studies of respiratory physiology in the newborn infant. III. Measurement of mechanics of respiration. Journal of Clinical Investigation, 36, 440-448.

DuBois, A. B., Botelho, S. Y., Bedell, G. N., Marshall, R., and Comroe, J. H., Jr (1956). A rapid plethysmographic method for measuring thoracic gas volume. A comparison with a nitrogen washout method for measuring functional residual capacity in normal subjects. Journal of Clinical Investigation, 35, 322-326.

Hack, M., Fanaroff, A. A., Klaus, M. H., Mendelawitz, B. D., and Merkatz, I. R. (1976). Neonatal respiratory distress following elective delivery. A preventable disease? American Journal of Obstetrics and Gynecology, 126, 43-47.
Humphreys, P. W., Normand, I. C. S., Reynolds, E. O., and Strang, L. B. (1967). Pulmonary lymph flow and the uptake of liquid from the lungs of the lamb at the start of breathing. Journal of Physiology, 193, 1-29.

Karlberg, P., Cherry, R. B., Escardó, F. E., and Koch, G. (1962). Respiratory studies in newborn infants. II. Pulmonary ventilation and mechanics of breathing in the first minutes of life, including the onset of respiration. Acta paediatrica Scandinavica, 51, 121-136.

Kjellmer, I., Magno, R., and Karlsson, K. (1974). Anesthesia for cesarean section. I. Effects on the respiratory adaptation of the newborn in elective cesarean section. Acta anaesthesiologica Scandinavica, 18, 48-57.

Magno, R., Karlsson, K., Selstam, U., and Wickström, I. (1976). Anesthesia for cesarean section. V. Effects of enflurane anesthesia on the respiratory adaptation of the newborn in elective cesarean section. Acta anaesthesiologica Scandinavica, 20, 147-155.

Magno, R., Selstam, U., and Karlsson, K. (1975). Anesthesia for cesarean section. II. Effects of the induction-delivery interval on the respiratory adaptation of the newborn in elective cesarean section. Acta anaesthesiologica Scandinavica, 19, 250-259.

Milner, A. D., Saunders, R. A., and Hopkin, I. E. (1977). Effects of continuous distending pressure on lung volumes and lung mechanics in the immediate neonatal period. Biology of the Neonate, 31, 111-115.

Reis, R. A., Gerbie, A. B., and Gerbie, M. V. (1970). Reducing hazards to the newborn during cesarian section. Surgery, Gynecology and Obstetrics, 130, 124-126.

Saunders, R. A., Milner, A. D., and Hopkin, I. E. (1976). The effect of continuous positive airway pressure on lung mechanics and lung volume in the neonate. Biology of the Neonate, 29, 178-186.

Sisson, T. R. C., Knutson, S., and Kendall, N. (1973). The blood volume of infants. IV. Infants born by cesarean section. American Journal of Obstetrics and Gynecology, 117, 351-357.

Usher, R. H., Allen, A. C., and McLean, F. H. (1971). Risk of respiratory distress syndrome related to gestational age, route of delivery and maternal diabetes. American Journal of Obstetrics and Gynecology, 111, 826-832.

Correspondence to Dr A. D. Milner, Department of Child Health, Medical School, Queen's Medical Centre, Nottingham NG7 2UH. 